\title{
Escolhas de livros de música para o espaço da escola: análise de alunos de um Curso de licenciatura em Música
}

\section{Maria Cecília Rodrigues Torres \\ (Centro Universitário Metodista - IPA)}

\begin{abstract}
Resumo: Este artigo apresenta e analisa questões que nortearam o trabalho realizado na disciplina de Didática do Ensino da Música com duas turmas de alunos do $3^{\circ}$. Semestre do Curso de Licenciatura em Música do Centro Universitário Metodista - IPA, em Porto Alegre -RS, ao longo dos semestres de 2009 II e 2010 I. Esta proposta está centrada na perspectiva de fazer interlocuções com outros trabalhos desenvolvidos com análise de materiais didáticos e que envolve pesquisas que estão sendo desenvolvidas por docentes e discentes dos cursos de Licenciatura em Música de três Instituições no Brasil. Este texto apresenta alguns aspectos musicais que constituíram o corpus de análise, qual seja o conjunto de livros de música que estes alunos selecionaram com o objetivo de poderem dialogar e trabalhar com estes materiais em sala de aula como educadores musicais da escola de educação básica.
\end{abstract}

Palavras-chave: Análise de livros, didática da música, aula de música, escola de educação básica.

\section{SELECTION OF MUSIC BOOKS FOR THE ENVIRONMENT OF THE SCHOOL: ANALYSIS OF STUDENTS OF A GRADUATION MUSIC COURSE}

\begin{abstract}
This article presents and analyzes questions that guided the activities performed on the subject of Didactics of Music Education with students from the $3^{\text {rd }}$ semester of the Music Teaching Course, at the Centro Universitário Metodista - IPA, in Porto Alegre - RS, throughout the second semester of 2009 and the first semester of 2010. The proposition is centered upon the perspective to dialogue with other works developed through the analysis of didactic materials with research involving teachers and students from Music Teaching Courses in three institutions. It presents a few musical aspects that formed this analysis corpus, that is, the collection of music books that these students have selected with the purpose of dialoguing and working with these materials in the fundamental school classroom as music teachers at the fundamental school.
\end{abstract}

Keywords: Books analysis, music didactics, music class, fundamental school.

\footnotetext{
1 Parte deste artigo foi apresentado no XIV Encontro da ABEM Sul em Maringá, em maio de 2011.
} 


\section{Introdução e apresentação do tema}

A temática da análise de materiais e livros de música para o espaço da escola de educação básica tem sido fonte de pesquisa por parte de educadores musicais em diversas Instituições e cursos superiores. Destaco entre os trabalhos na perspectiva da análise de manuais e métodos para ensino de música e de instrumentos as investigações realizadas por Souza et al. (1997), Gonçalves e Costa (2002), Dametto (2004), Torres (2004 e 2009), Oliveira (2005), Souza, Torres, Gonçalves e Oliveira (2009), Garbosa ( 2009), Reys e Garbosa (2010), dentre outros. Desta forma ressalto ao longo deste artigo alguns dos objetivos e procedimentos metodológicos que embasaram a opção de desenvolver esta proposta de atividade com alunos de um Curso de Licenciatura em Música enquanto cursavam a disciplina de Didática do Ensino da Música.

Chamo a atenção para o fato de que desde 2004 venho desenvolvendo estudos sobre a temática análise de livros e manuais para ensino de instrumento, com uma primeira investigação a partir de cinco métodos para ensino de violino, feita na minha perspectiva como aluna que conviveu com muitos destes materiais por mais duas décadas. Neste estudo selecionei quatro métodos com os quais convivi como estudante de violino em aulas particulares entre as décadas de 60 e 80 e um quinto material que conheci em outra oportunidade, como professora estagiária durante um período em uma Escola de Música na região da Toscana (Itália), na década de 90. Chamo a atenção ainda para o fato que

Durante a análise desses manuais foram observados também aspectos relativos à cronologia das composições e períodos musicais, breve história dos instrumentos, fotos com pessoas segurando os instrumentos e executando posições e dedilhados musicais, além de gravuras ilustrando algumas melodias (Torres, 2004, p.44).

Uma outra proposta de análise de materiais foi delineando-se no decorrer das disciplinas de Metodologia e Prática do Ensino da Música I e II, do Curso de Licenciatura em Música da FUNDARTE-UERGS, como uma possibilidade de conhecer e socializar os métodos e manuais para ensino de instrumentos que os 
alunos do quarto semestre do Curso selecionavam e, que provavelmente usariam nas suas práticas musicais em sala de aula. Este exercício com os alunos gerou reflexões e instigou uma análise minuciosa destes materiais, muitas vezes já manuseados e utilizados pelo grupo e o que, certamente, despertou estranhamentos e descobertas.

Houve também uma atividade de análise de manuais para ensino de flauta doce que foi realizada na disciplina de Flauta doce no Contexto escolar, disciplina esta que é ofertada durante o segundo semestre do Curso de licenciatura em Música do IPA, com o objetivo dos alunos conhecerem e selecionarem métodos e manuais para trabalharem com flauta doce no espaço da escola regular e com possibilidades de desenvolverem atividades musicais com grupos de mais de 20 alunos em sala de aula.

Sobre a proposta de analisar métodos ou manuais e a conceituação destes termos, trago um trecho do trabalho de Reys e Garbosa (2010) no qual as autoras enfatizam que o artigo propõe “uma reflexão acerca do termo 'método' utilizada tradicionalmente no campo do ensino instrumental como referência ao livro didático destinado ao aluno iniciante". Elas finalizam a argumentação e pontuam que "a reflexão se faz necessária tendo em vista a multiplicidade de significados que o termo adquire nas áreas de Educação e Música" (2010, p.48).

Ainda na perspectiva de apresentar e discutir sobre métodos para ensino de música, trago este excerto de Penna (2011) no sentido de desencadear uma reflexão sobre o termo método e seus usos e significados. A autora enfatiza que

No cotidiano da área da música, o termo método muitas vezes refere-se simplesmente ao material didático que traz uma série de exercícios - assim, por exemplo, fala-se do "método $\mathrm{x}$ de flauta doce", "tal método de violão popular" etc. Voltados para o aprendizado de instrumentos, métodos desse tempo são constituídos por uma sequenciação progressiva exercícios e/ou de repertório que seus autores têm usado com seus alunos e que tem dado certo, tem "funcionado" para o domínio técnico de um fazer musical (Penna, 2011, p.14-15). 
Desta forma ressalto que o foco deste artigo é sobre a análise de livros de música para serem trabalhados no espaço das aulas de música na escola como materiais pedagógico musicais.

\section{Análise de livros na aula de Didática da Música}

A partir desta breve apresentação sobre as articulações entre este tema e a minha trajetória, elenco algumas questões para pensarmos sobre este Projeto que escolhi para ser desenvolvido ao longo desta disciplina, durante o terceiro semestre do Curso de Licenciatura em Música do IPA. Pensei ainda que por ser o semestre que antecede ao início das práticas musicais em sala de aula com o estágio supervisionado I, esta pesquisa poderia auxiliar na elaboração das condutas com as estratégias metodológicas e os planejamentos das aulas de música.

O que uma proposição de atividade a partir da seleção de livros de música que cada um dos alunos usaria no espaço da escola regular durante uma aula de música tem em comum com as reflexões geradas no espaço desta disciplina? Como organizar e selecionar questões pertinentes que auxiliem na ficha de análise dos livros e que sejam comuns a todos os alunos? Quais aspectos didáticos e musicais priorizar nestes itens para a confecção dos tópicos de análise? Quais são as relações entre esta proposta de escolher livros e fazer a análise dos mesmos levando em conta um mesmo roteiro distribuído pela professora e as discussões no campo da Didática da Música?

Ao listar estas perguntas e, com o propósito de que muitos outros questionamentos fossem surgindo por parte dos alunos e também de minha parte, iniciei a organização desta ficha de avaliação a partir de resultados e análise de pesquisas desenvolvidas por Souza, Torres, Oliveira e Gonçalves (2009) e por Torres (2009). O objetivo foi de que os alunos pudessem ter um mesmo roteiro de perguntas como norteador das análises. Destaco que esta organização foi fundamental tanto para eu pensar os rumos das análises dos livros quanto para os alunos desempenharem a tarefa. 
A seguir apresento algumas das perguntas que constituíram as fichas de análise e que tiveram como primeira demanda a questão com uma justificativa pela escolha de um determinado livro, assim como a explicitação se haviam trabalhado com ele como alunos ou com professores de música, por considerar este tópico essencial para conhecer e desvelar aspectos pedagógicos musicais que mereceram destaque em cada uma das análises, assim como as concepções de música e aula de música que permeavam as narrativas dos textos.

De que maneira os acervos de livros ou manuais didáticos abordam conteúdos de música? Como desvelam contextos institucionais e pedagógicomusicais que estariam constituindo a disciplina música? Quais conteúdos musicais (assuntos em geral, repertório, procedimentos de ensino) circulavam nos livros encontrados nos referidos acervos? (Souza, Torres, Gonçalves e Oliveira, 2009, p.38).

A partir destas questões organizei uma ficha com onze questões que foram selecionadas a partir dos dados da pesquisa de Souza et. al (2009) e complementei com os dados de identificação do livro. Cada aluno recebeu o material no início da atividade e trouxe o livro que havia escolhido para realizar a análise.

Título do livro:

\section{Análise de livros para ensino de música na escola}

Autores:

Editora: Ano

Número de páginas: Número de capítulos:

1. Justifique os motivos de sua escolha por este livro e explicite se já trabalhou com ele como alunos ou como professor de música:

2. Qual é a faixa etária de alunos para trabalhar com este material?

3. De que maneira este livro aborda conteúdos de música?

4. Como desvela contextos institucionais e pedagógicos-musicais que estariam constituindo a disciplina música?

5. Quais conteúdos musicais (assuntos em geral, repertório, procedimentos de ensino) circulam neste livro?

6. De que forma os conteúdos são selecionados, seqüenciados e organizados?

7. Quais são as concepções de música e de ensino de música implícitas e/ou explícitas no seu conteúdo?.

8. Quais as características das ilustrações no material encontrado?

9. Que práticas de ensino de música podem ser desveladas na apropriação desse material? Que atividades musicais proposta ou apresentadas neste livro você escolheria para trabalhar em sala de aula?

10. Quais estratégias de adequação deste livro às políticas educacionais federais e estaduais da época de sua publicação?

11. Que outros comentários faria a respeito do livro que selecionou? 


\section{Procedimentos: escolher um livro}

Como já ressaltei anteriormente, esta proposta foi desenvolvida com duas turmas de alunos que cursavam a disciplina de Didática de Ensino da Música, num total de 60 alunos, sendo 35 alunos da turma da noite e 25 da turma da tarde. A primeira etapa do trabalho foi de cada um selecionar e trazer para a próxima aula um livro de música que utilizaria em uma aula de música na escola. No dia combinado para o início da tarefa nem todos os alunos haviam trazido os livros, mas a grande maioria tinha selecionado algum e eu levei alguns exemplares para aqueles que estavam com o material pedido. Ressalto que em uma das turmas uma colega levou uns cinco livros para emprestar para os colegas, pois ela já atua como professora de música na escola e tem livros com os quais trabalha na aula de música. Desta maneira todos os alunos tiveram livros para análise e começamos assim a atividade em sala de aula, com a leitura e discussão da ficha de análise e o esclarecimento de dúvidas a respeito de cada tópico.

Embora meu objetivo fosse de que cada aluno escolhesse o seu livro, optei por levar alguns livros para empréstimo e realização da análise, posto que ao longo da disciplina apresentei algumas sugestões bibliográficas para se trabalhar com música na escola de educação básica e havia levado alguns títulos para mostrar para as turmas.

\section{O corpus de análise}

\section{Títulos dos livros}

1. Descobrindo o universo da música: ideias para a sala de aula

2. Explorando o universo da música

3. Música na educação infantil

4. Práticas de ensinar música

5. Elementos da linguagem musical

6. Flauta doce: método de ensino para crianças

7. A educação artística da criança (Plástica e Música): fundamentos e atividades

8. Lenga La Lenga

9. Instrumentos da Orquestra: cadernos da

\section{Autores}

Elizabeth Krieger

Nicole Jeandot

Teca Alencar de Brito

Teresa Mateiro e Jusamara Souza (Org.)

Bruno Kiefer

Nereide Schilaro Santa Rosa

Arlete de Oliveira Lima e Heloisa Lopes

Viviane Beineke e Sérgio Paulo Ribeiro de Freitas

Roy Bennet 
Universidade de Cambridge

10. A orquestra Tintim por tintim

11. Guia para Educação e prática musical em escolas

12. Turma da música

13. Ensinando música musicalmente

14. Música na Educação Básica - 10, vol. ABEM

15. Como ouvir (e entender) música

16. Estudos de Psicopedagogia musical

17. Iniciação musical, brincando e criando

18. Palavras que cantam

19. Brincando e muscializando (com os sons)

20. Alegria, Alegria

21. Elementos Básicos da música

22. Para fazer música

23. Brincando com a música: flauta doce e teclado

24. O som e o sentido: uma outra história da música

25. Nossa bandinha

26. Exercícios de teoria musical

27. O mundo dos sons

28. Curso completo de Teoria e Solfejo

29. A semínima solitária

30. Aprendendo e brincando com a música

31. Brincando com música: a descoberta das notas

32. Teoria da Música

33. Brincadeiras no teclado

34. Como usar a música em sala de aula

35. Vêm amigo, vêm cantar

36. Brincadeiras cantadas

37. Brincando com música: como nasce a música

38. Aprender a compor

39. Música em diálogo - Ações Interdisciplinares na Educação Infantil

40. Arranjos de músicas folclóricas

41. Música para professores

42. Princípios básicos da música para a juventude

43. Música, cotidiano e educação

44. Koellreutter Educador

45. Hip Hop: da rua para a escola

46. O mundo encantado da música Vol.I

47. La iniciácion ao piano
Liane Hentschke et al. (Org.).

Márcia Visconti e Maria Biagioni

Cecília Cavalieri França

Keith Swanwick

Luciane W. F. Garbosa (Editora)

Aaron Coplan

Violeta Hemsy de Gainza

Josette Silveira Feres

Jusamara Souza et al. (Org.)

Marlei da Silva Novais

Carlos Felipe e Giselle Vargas

Roy Bennet

Cecília Cavalieri França

Carla Magnan e Gabriella Solari (Org.)

José Miguel Wisnik

Elvira Drummond

Marisa Rosa de Lima e Sérgio

Luiz Ferreira de Figueiredo

Carla Magnan e Gabriella Solari (Org.)

Belmira Cardoso e Mário Mascarenhas

Patrícia Mauro e Sérgio Conforti

Chizuko Yogi

Carla Magnan e Gabriella Solari (Org.)

Bohumil Med

Maria Thereza Ferreira

Martins Ferreira

Isolde Mohr Frank

Rose Marie Reis Garcia e Lílian

Argentina Marques

Carla Magnan e Gabriella Solari (Org.)

John Howard

Caroline Cao Ponso

Jusamara Souza et al. (Org.)

Jusamara Souza, Liane Hentschke e Cristina Rolim Wolffenbüttel (org).

Maria Luisa Priolli

Jusamara Souza (Org.)

Teca Alencar de Brito

Jusamara Souza, Vania Fialho e Juciane

Araldi

Nilsa Zimmermamm

Violeta Hemsy de Gainza 
Chamo a atenção para o fato de que mantive os nomes dos livros e os autores conforme as informações dos alunos nas fichas de análise, sem correções ou modificações e que são estes que constam na listagem dos livros selecionados.

\section{Entre justificativas e práticas musicais}

Juntei os tópicos das justificativas com os das atividades musicais que escolheriam para trabalhar em sala de aula e faço uma síntese de algumas das respostas apresentadas. A seguir apresento quatro excertos dos alunos e destaco que os nomes são fictícios e escolhidos por mim, no sentido de manter o anonimato dos mesmos no trabalho.

Eu não dispunha de nenhum livro didático, apenas métodos de instrumentos musicais e similares, então pedi auxílio de uma colega que emprestou-me pois buscava um livro com bases didáticas que pudessem dar-me suporte para elaborar uma aula futuramente (Cássio, Descobrindo a Música).

O livro apresenta de forma bastante clara e lúdica exercícios relacionados aos conteúdos trabalhados no ensino fundamental, inserindo a música como interface ao aprendizado destes conteúdos, ao mesmo tempo que trabalha as aptidões musicais dos alunos (Arthur, Aprendendo e brincando com Música vol.1).

Dentre as obras que possuo em casa esta é a mais didática e destinada à prática docente (Rafael, Princípios básicos da música para a juventude).

Este livro baseia-se em experiências realizadas em sala de aula, fundamentase nos métodos de Kodály e Dalcroze. Um livro para ser trabalhado com as séries iniciais do ensino fundamental, o qual busca aproximar a realidade de nossas crianças com a música. Já trabalhei como professora de música com crianças de seis á dez anos, utilizando como "base" este livro e obtive bons resultados (Clara, O mundo Encantado da Música Vol. I - Dó, Ré, Mí).

Dentre as justificativas selecionadas encontramos respostas diversas que mesclam as escolhas pelos livros já conhecidos e trabalhados em sala de aula aos 
livros emprestados e sugeridos pelos colegas com foco nas questões didáticas e musicais.

No tópico referente às práticas de ensino de música analisadas e destacadas pelos alunos, ressalto os seguintes comentários:

Todas são propostas muito ricas em termos de conteúdos musicais e, com certeza, é um livro indispensável para qualquer professor que visa trabalhar especificamente na área da educação básica, tanto em escolas particulares, estaduais ou até mesmo em projetos sociais (José, Música na Educação Básica, vol.1).

O livro não propõe atividades mas mostra o rap como um possível tema a ser abordado na sala de aula. A partir das características particulares do rap podemos desenvolver atividades para a sala de aula como, por exemplo, compor um rap com os alunos e apresentá-lo para a escola [...] (Carlos, HipHop - da rua para a escola).

Como o livro aborda músicas diversificadas, ou seja, de várias localidades proporia um trabalho relacionado com esta diversidade, como exemplo, "o dia dos estados brasileiros", ensinando canções respectivas (Caroline, Vêm amigos, vêm cantar: coletânea de canções para escola e grupos em geral).

Destaquei estes excertos para apresentar nos limites deste artigo, mas emergiu uma riqueza de comentários ligados aos modos de ler e analisar cada um destes livros, na perspectiva da singularidade dos leitores e de suas leituras e que subsidiaram a minha avaliação e a reorganização desta atividade no contexto de uma disciplina de um curso de Licenciatura em Música.

Finalizo estas reflexões sobre este tema que tem me acompanhado ao longo dos últimos anos, tanto nas práticas pedagógicas em sala de aula quanto nos momentos de orientação dos estágios supervisionados em Música nas escolas de educação básica. Ora estou atuando como professora de Didática ou Prática Pedagógica IV para os alunos, ora estou nas reuniões de orientação dos estágios com as leituras, planejamentos e observação das docências nas aulas de músicas e envolvida com esta temática dos livros e materiais que cada um seleciona para trabalhar com seus alunos. 
O retorno positivo dos alunos através da avaliação desta proposta de selecionar e analisar livros tem acontecido ao final de cada semestre letivo e certamente tem sido um dado fundamental para eu rever a validade de continuar a trabalhar com esta atividade e modificar ou acrescentar outras questões. Desta forma posso conhecer concepções musicais dos alunos com suas análises e também propiciar um espaço de socialização e análise dos materiais que muitos já utilizam em suas práticas pedagógico musicais, assim como oportunizar o conhecimento de outros títulos da bibliografia específica da área da Educação Musical no sentido de subsidiar reflexões e proposições pedagógico musicais para as aulas de música na escola de Educação Básica.

\section{Referências}

DAMETTO, Verônica. Análise crítica e comparativa dos métodos pedagógicos de piano de Antonio leal, de Sá Pereira e de José Alberto Kaplan, sob o aspecto metodológico da técnica pianística. In: GOBBI, Valéria (Org.). Questões em Música. Passo Fundo: editora da UPF, 2004, p.165-176.

GARBOSA, Luciane Wilke Freitas. Contribuições teórico-metodológicas da história da leitura para o campo da educação musical: a perspectiva de Roger Chartier. Revista da ABEM, n. 22, Porto Alegre, p.19-29, 2009.

GONÇALVES, Lilia Neves; COSTA, Maria Cristina Lemes S. O projeto Conteúdos de música em livros didáticos: resultados parciais. In: ENCONTRO ANUAL DA ABEM, 11., 2002, Natal. Anais... Natal: ABEM, 2002.

OLIVEIRA, Fernanda de Assis. Materiais didáticos nas aulas de música: um survey com professores da Rede Municipal de Ensino de Porto Alegre. Dissertação de Mestrado no PPGE Música- Mestrado-Doutorado UFRGS, 2005.

PENNA, Maura. Introdução. MATEIRO, Teresa, ILARI, Beatriz. Pedagogias em Educação Musical. Curitiba: Editora IBPEX, 2011, p.13-24

REYS, Maria Cristiane, GARBOSA, Luciane Wilke Freitas. Cello mit Spass und Hugo: O método de Gerhard Mantel, análise e leituras. In: XX Congresso da ANPPOM, Anais... Florianópolis, 2010.

SOUZA, Jusamara, TORRES, Maria Cecília A. R, GONÇALVES, Lilia Neves, OLIVEIRA, Fernanda. A construção da música como uma disciplina escolar: um estudo a partir dos livros didáticos In: ENCONTRO ANUAL DA ABEM, 18. 2002, Londrina. Anais... Londrina: ABEM, 2009. 
TORRES, Maria Cecília A. R. Entre livros e métodos musicais para ensino de instrumentos: diferenças e semelhanças. In: GOBBI, Valéria (Org.). Questões em Música. Passo Fundo: editora da UPF, 2004, p.42-56.

TORRES, Maria Cecília A. R. Olhares de alunos de um Curso de Licenciatura em Música: entre métodos e manuais para ensino de instrumento. Revista da FUNDARTE, Montenegro: Editora da FUNDARTE, ano 9, n.17, janeiro- junho 2009, p.25-29. 